\title{
Comparison of the Holt-Winters Exponential Smoothing Method with ARIMA Models: Forecasting of GDP per Capita in Five Balkan Countries Members of European Union (EU) Post COVID
}

\author{
Melina Dritsaki¹, Chaido Dritsaki² \\ ${ }^{1}$ Department of Economics, University of Western Macedonia, Kastoria, Greece \\ ${ }^{2}$ Department of Accounting and Finance, University of Western Macedonia, Kozani, Greece \\ Email: mdritsaki@uowm.gr, cdritsaki@uowm.gr
}

How to cite this paper: Dritsaki, M., \& Dritsaki, C. (2021). Comparison of the Holt-Winters Exponential Smoothing Method with ARIMA Models: Forecasting of GDP per Capita in Five Balkan Countries Members of European Union (EU) Post COVID. Modern Economy, 12, 1972-1998. https://doi.org/10.4236/me.2021.1212104

Received: October 3, 2021

Accepted: December 27, 2021

Published: December 30, 2021

Copyright $\odot 2021$ by author(s) and Scientific Research Publishing Inc. This work is licensed under the Creative Commons Attribution International License (CC BY 4.0). http://creativecommons.org/licenses/by/4.0/

\begin{abstract}
Gross Domestic Product (GDP) is the most frequently used measure of total product in an economy while GDP per capita is used for comparing living conditions or for watching the convergence or divergence among member countries of European Union (EU). This paper presents how two techniques can be applied to the same data set and how their performance can be evaluated and compared. We chose ARIMA model and Holt-Winters exponential smoothing method to forecast the GDP per capita of five Balkan countries-members of EU and to find the model that provides more accurate prediction. To achieve this, we apply the Root Mean Square Error (RMSE), the Mean Actual Error (MAE), the Mean Actual Percentage Error (MAPE), the Symmetric Mean Absolute Percentage Error (SMAPE) criteria and Theil's U statistics. Based on statistical metrics ARIMA is the best forecasting model and fits performance for the examined period in four out of five countries.
\end{abstract}

\section{Keywords}

GDP per Capita, ARIMA, Holt-Winters, Zivot-Andrews, Forecasting, Balkan Countries of EU

\section{Introduction}

Long-term economic growth corresponds to a constant increase of per capita national production. Models of economic growth are based on the production 
function and describe the relationship between capital labour force, natural resources (land and raw materials) and level of technology. As a result, economic growth is achieved either through the increase in capital (primarily through investments) or through labour force (primarily specialised labour) or through natural resources (primarily through raw materials) or through technology or all the aforementioned. The faster the rate of production growth, the more likely the economy will secure a higher rate of GDP growth.

Those responsible for exercising economic policy, evaluate each country's condition by using GDP as an index of economic development as it represents the overall statistic element of economic activity. Nevertheless, GDP has been criticised as it does not take into account non-market economic activities. Moreover, GDP does not reflect the possible negative impact of economic growth in relation to natural resources and the environment. Various economists use the GDP per capita as an index of economic growth, in order to compare the wealth of one country with another. Forecasting GDP per capita using econometric techniques is very important both at a theoretical as well as a practical growth level of a country and also for exercising its future monetary policies.

The global financial and economic crisis led the EU-27 to recession in 2009. After the shrink in all member-countries of EU, the economies of 23 member countries recovered in 2010 while an increase was recorded next year for 23 member countries. Afterwards, all 27 member countries recorded positive percentage variation in 2017 as well as 2018 and 2019. But, the damages caused by COVID-19 in the Eurozone economies were devastating as the economy on Eurozone reduced in size by $15 \%$ in the second semester 2020 in comparison to the corresponding semester of 2019. The GDP of EU-27 was expected to shrink by $7.4 \%$ in 2020. Probably, it may not recover in levels before crisis during 2021, increasing the risk of unreliability and job losses.

The adjusted GDP in relation to its population is often used for the evaluation of standard of living. In 2019, the GDP per capita for EU-27 (current prices) was 31.1 thousand euros. Prices, expressed in purchasing power parity (PPP), have been adjusted in order to take into account the differences in price levels among countries. Each individual country can be compared with the average of EU-27, which has been denoted with 100. Based on this measure, GDP per capita in (PPP) is 53 in Bulgaria, in Croatia 65, in Greece 68, Romania 69 and Slovenia 88. All five Balkan countries that we examine are below par of EU.

\subsection{What Makes the Balkan Case Interesting?}

In the change of the new century, Balkans does not have enough things to celebrate. With the exception of Greece, in the rest of the countries the 20s were, the least to say, an adventure and in some cases a nightmare. Going through the grey past of the Cold War and the limited expectations in the lost, uncertain and disastrous decade of 1990, Balkan countries could now evolve into a domain of dynamic economic growth and prosperity for the benefit of their citizens, as long as they take advantage of the significant investment opportunities raised due to 
their geo-economic position and their comparative advantages.

Due to their geographical location, the rich natural resources, the combination of Mediterranean and continental climate and the power of their human capital, Balkans are located in a very favourable position with significant environmental comparative advantages. With a capable political initiative, intellectual potential, leadership for the society and eagerness to learn from the past, Balkans countries could build an economic development and become role-models for the European continent.

The economic challenges faced by the Balkan countries today, provide an opportunity for reform, which not only can place them into the right developmental pathway, but also can revitalise its young democracies. The people who live in the Balkans are seeking a development which will provide employment, a decent lifestyle as well as promoting a balanced and prudent use of natural resources. When it comes to partnership issues about a joint green economy, regions do not start from scratch. The Energy Community Treaty which was signed in Athens in 2005 represents a starting point, since it shows that a region can support treaties for the development of single markers based on common interests and solidarity. It proves that Balkan countries can prepare themselves, not only to obtain and make a proper use of European support, but also contribute essentially to its stability, growth and energy self-sufficiency of the EU.

Moreover, the relations of the EU with Western Balkans work under the frame of stability procedures and cooperation. They aim at the political stability of the countries and enabling their transition to a market economy, also at the boost of cooperation at a region level (due to their history) and the promotion of their inclusion in the EU. The security, the political and social stability, the economic growth as well as the possibility of their inclusion in the EU, contain the key to foreign direct investment in the region.

\subsection{What Does the Paper Contribute to the Understanding of Economic Processes?}

Human resources are a significant determinant of economic growth and progression as well as a source of competitive advantages. Balkan countries could benefit from an improved competitiveness in labour market together with increased investments at the sectors of education, science and technology, resulting to a skilled workforce. The steps followed in order to enhance human capital in combination with the increased labour mobility, can stimulate the general competitiveness, mitigate poverty and reinforce governance in all levels. Education is the cornerstone of economic region development and its integration to the European and global community.

The close cooperation on issues of practical educational initiatives could benefit the life and perspectives of all civilians. Moreover, the Balkan region attracts the admiration because of its impressive coastlines, gastronomic heritage, cultural traditions and agricultural goods which attract thousands of tourists every year. Also, the economic power of tourism could potentially be expanded from 
regional tourist initiatives which praise the cultural heritage and diversity while strengthening the region infrastructure by connecting individual countries. Such initiative would have generated economic income to agricultural an urban societies in the whole region while strengthening the relation between people.

\subsection{What Does the Paper Contribute to the GDP Forecasting Methodology?}

Forecasts combine expert judgement with a variety of existing and new information related to current and future developments. These include recent statistical results, combined with analyses based on econometric models and techniques. An important starting point in the forecasting process is the re-appraisal of economic climate of the countries and the general global economy. This index is measured in terms of growth compared to previous year.

For the case of Eurozone and G7 economies, the short-term assessment includes indices which provide estimations of the short-run increase of GDP. These models combine information from "soft" indices, namely business climate, as well as "hard indices" such as industrial production and use different data frequencies as well as a variation of estimation techniques (see Sédillot \& Pain, 2003; Mourougane, 2006). Nevertheless, statistical model indices are limited to their capacity to forecast quarterly increase of GDP, since the confidence intervals for the GDP estimations for the next quarter is $70 \%$ and is fluctuated between 0.4 and 0.8 percentage points depending on the country or region and uncertainty exists as long as the forecasting period is being extended. Forecasting error could also occur for various reasons such as revisions of the initial database, such as revisions of the original data.

A popular generation of forecasting tools being used to predict and control future values of phenomena, is the Box-Jenkins methodology known as the ARIMA methodology. Box and Jenkins have proved that their method is strong, especially when generating forecasts of short-run time series. In general, we could say that ARIMA models outweigh most sophisticated structural models in terms of its short forecasting ability. This methodology has been used extensively from many researchers in forecasting studies. The popularity of this method is due to the fact that it has proven its ability to accurately predict if all the conditions of its application are fulfilled.

The Holt-Winters method or algorithm allows users to smooth a time series and use data in order to forecast areas of interest. The exponential smoothing yields exponentially declining weights and values versus historical data to reduce the weight value for older data. In other words, we could say that more recent historic data are assigned more weight in forecasting than the older results. Box-Jenkins methodology, as well as Holt-Winters methodology, is considered dynamic linear model and part of the Bayesian approach.

In this paper, a comparative analysis is presented using two widely used linear models in order to forecast the per capita GDP in Balkan countries, member countries of EU (Bulgaria, Croatia, Greece, Romania, and Slovenia).The models 
are Autoregressive Integrated Moving Average (ARIMA) model and Holt-Winters model. These models have an adaptive ability to face linearity in problem solving (Makridakis et al., 1982). The aim of this paper is to find the model that provides more accurate prediction. The comparison is made by considering the smallest values of the Root Mean Square Error (RMSE), the Mean Actual Error (MAE), the Mean Actual Percentage Error (MAPE), the Symmetric Mean Absolute Percentage Error (SMAPE), and the Theil's U statistics for prediction based on the annual time series.

The rest of the paper is organized as follows: Section 2 describes the literature review while in Section 3 the theoretical background is given. Data and descriptive statistics gross domestic product at current prices per head of population provided in Section 4. In Section 5 the empirical results are presented. In Section 6 we discuss the applicability of employing the Box-Jenkins and Holt-Winters methodologies on GDP forecasting and share some thoughts on GDP forecasting in general and finally, summary and conclusions are provided in Section 7.

\section{Literature Review}

The most suggested forecasting models, analyzed by many researchers, use the statistical method as a forecasting tool for future data. In the analysis of statistical data there are various forecasting methods, like Box-Jenkins methodology and exponential smoothing techniques of Holt-Winters. These techniques provide forecasting models of different accuracy. Model's accuracy is based on the minimum forecasting error. The suitable forecasting models are based on various factors such as prediction interval, forecasting period, the characteristic and the size of time series (Makridakis et al., 1998). We present some papers related with forecasting of economic growth which either used the Box-Jenkins technique or the Holt-Winters exponential smoothing technique.

On their paper Samimi, Shirazi and Fazlollahtabar (2007), used quarterly data from 1998-2003 to forecast the GDP of Iran with exponential smoothing method and artificial neural network approaches for quarterly periods 2004-2005. The results of the paper shown the neural network approach provided with better results the GDP forecasting of Iran.

Wei et al. (2010) used yearly GDP data from the province of Shaanxi in China between 1952 and 2007 in order to forecast the province's GDP for the following 6 years. Applying the ARIMA $(1,2,1)$ model, they found out that the GDP of this province has an impressive upward trend. Moreover, the results of this study suggest that the error between real and predicted GDP value lies within the 5\% interval.

The paper of Dong and Zhu (2014) aims at forecasting per capita GDP for eight autonomous regions in Yunnan State of China. The exponential smoothing method and corrected exponential smoothing method were those used for the forecasting of the examined variable. The results showed that the modified exponential smoothing model (MESM) was more effective. The innovation of this 
paper is that it was based on data collected by eight places while normally a model is based on data from one place.

Dritsaki (2015) used the Box-Jenkins methodology, with an ARIMA $(1,1,1)$ model, between 1980 and 2013 in order to forecast the real GDP in the case of Greece. The results showed that real GDP values outside the sample were improving steadily.

Galadima (2016) attempted to model and forecast the per capita income in the case of Nigeria using yearly data from 1960 to 2015. Using the Box-Jenkins methodology, the study found out that the best model is the ARIMA $(1,1,1)$. The forecasting based on the assessed model for 5 years shown impressive results in the case of the real per capita income for the sampling period with the minimum error in the model.

Uwimana et al. (2018) used the ARIMA models in order to forecast the GDP of the 20 biggest economies in Africa. Based on the results of their assessments, they suggest that between 1990 and 2030, there will be an increasing trend of GDP whereas the mean economic growth of Africa would reach $5.52 \%$ and the GDP could reach between 2185.21 and 10,186.18 billion US dollars.

The aim of the paper of Oral (2019) was to compare the selected exponential smoothing methods for forecasting the indices of economic growth in Turkey and to determine the most suitable technique. The results of their paper showed that the additive Holt-Winters smoothing exponential model is the most appropriate method for seasonality forecasting of Turkey's economic growth indices.

Nyoni and Muchingami (2019) use yearly data of the GDP per capita of Botswana from 1960 until 2017 as well as Box-Jenkins methodology and found out that the optimum model for the data under examination is the $\operatorname{ARIMA}(3,2,3)$ one. The study results show that Botswana's living standards will continue to improve during the next decade.

da Costa et al. (2020) investigate the effectiveness of time series classical models and the state space models, which are applied on Brazil's GDP. The models used were Seasonal Autoregressive Integrated Moving Average (SARIMA) and a Holt-Winters method, which are considered as classical time series models and the dynamic linear model particularly a state-space model. According to statistical measures on model comparisons, the dynamic linear model exhibited the best forecasting model and the most appropriate fit performance for the examined period incorporating the significance of growth rate structure.

Finally, Eissa (2020) applied yearly data in order to forecast the GDP per capita in the case of Egypt and Saudi Arabia. Using Box-Jenkins methodology, the results suggest that ARIMA $(1,1,2)$ and $\operatorname{ARIMA}(1,1,1)$ models are the most appropriate to assess the GDP per capita for both countries. Also, the study outcomes suggest that there will be an increase of per capita GDP in both countries.

The per capita GDP is an important economic index which collects practical information helping policy makers in decision making. In this framework, the forecasting of per capita GDP is becoming a powerful tool for decision optimization in various sectors. The majority of studies dealt with GDP, used ARIMA 
models or Holt-Winters models and focused in one country. The present paper analyzes and compares the per capita GDP for five Balkan countries members of European Union using both ARIMA models as well as Holt-Winters model. Economic policy makers can take into consideration the forecasting per capita GDP after 2020 (pandemia year) in order to compare the growth levels and to cooperate more close with other Balkan countries leading them to prosperity.

\section{Theoretical Background}

The procedures of time series consist of simple forecasts and smoothing methods, correlation analysis methods and ARIMA modeling. Simple forecasting methods and smoothing are based on the idea that reliable forecasts can be accomplished with modeling patterns on the data, which are usually visible on a time series plot, and afterwards with the extension of these patterns in the future. The choice of method should be based on whether the patterns are static (constant in time) or dynamic (changes in time), on the nature of trend and seasonal components and how far we want to forecast. The simple forecast and smoothing methods model data on a series and are quite easy with a time series diagram. This approach decomposes the data through its components' parts and afterwards extends the estimation of these components in the future for forecasting. Exponential smoothing is another category of data analysis during time. Data smoothing is considered either with some optimum weight produced by data estimation or is achieved with a given weight. The optimum weight of ARIMA model is gained by fitting the $\operatorname{ARIMA}(0,1,1)$ model which stores the fits. The smoothing values on ARIMA model fit but one time lag unit.

\subsection{Testing for Stationarity}

Advances on global economy during the last years, after the recession and pandemia, have shaken many economies worldwide. As the period that is examined in this paper contains these advances, it was advisable to use a unit root test containing these variations. Appropriate information concerning the unknown structural variations (breaks) help policymakers on the design of long run policy examining these structural breaks. Zivot and Andrews (1992) suggested three models for the examination of unit root which are the following:

Model A allows for a one-time change in the intercept.

$$
\Delta y_{t}=\hat{\mu}^{A}+\hat{\vartheta}^{A} D U_{t}+\hat{\beta}^{A} t+\hat{\alpha}^{A} y_{t-1}+\sum_{j=1}^{k} \hat{\gamma}_{j}^{A} \Delta y_{t-j}+\hat{e}_{t}
$$

Model B is used to test for stationarity of the series around a broken trend.

$$
\Delta y_{t}=\hat{\mu}^{B}+\hat{\beta}^{B} t+\hat{\rho}^{B} D T_{t}^{*}+\hat{\alpha}^{B} y_{t-1}+\sum_{j=1}^{k} \hat{\gamma}_{j}^{B} \Delta y_{t-j}+\hat{e}_{t}
$$

Model C accommodates the possibility of a change in the intercept as well as a broken trend.

$$
\Delta y_{t}=\hat{\mu}^{C}+\hat{\vartheta}^{C} D U_{t}+\hat{\beta}^{C} t+\hat{\rho}^{C} D T_{t}^{*}+\hat{\alpha}^{C} y_{t-1}+\sum_{j=1}^{k} \hat{\gamma}_{j}^{C} \Delta y_{t-j}+\hat{e}_{t}
$$


where $D U_{1}$ is a sustained dummy variable capturing a shift in the intercept, and $D T_{t}^{*}$ is another dummy variable representing a shift in the trend occurring at time TB.

$$
\begin{gathered}
D U_{t}= \begin{cases}1, & \text { if } t>\mathrm{TB} \\
0 & \text { otherwise }\end{cases} \\
D T_{t}^{*}= \begin{cases}t-\mathrm{TB}, & \text { if } t>\mathrm{TB} \\
0 & \text { otherwise }\end{cases}
\end{gathered}
$$

Null hypothesis in all three above models is $\hat{\alpha}=0$ which entails that $y_{t}$ time series contains a structural break but is not stationary. Alternative hypothesis is $\hat{\alpha}<0$ meaning that time series is a stationary procedure with an endogenous time structural break taking place in an unknown point in time TB.

\subsection{ARIMA Models}

An Autoregressive Integrated Moving Average (ARIMA) model is a generalization of an Autoregressive Moving Average (ARMA) used in econometrics. ARIMA is one of the types of models in the Box-Jenkins methodology (Box \& Jenkins, 1976) for analysis and forecasting a time series (see Dritsaki \& Dritsaki, 2020).

The ARIMA $(p, d, q)$ can be expressed as:

$$
\left(1-\sum_{i=1}^{p} \varphi_{i} L^{i}\right)(1-L)^{d}\left(y_{t}-\mu\right)=\left(1-\sum_{j=1}^{q} \vartheta_{j} L^{j}\right) e_{t}
$$

where

$$
\varphi_{p}(L)=1-\sum_{i=1}^{p} \varphi_{i} L^{i} \text { and } \vartheta_{q}(L)=1-\sum_{j=1}^{q} \vartheta_{j} L^{j} \quad \text { are polynomials in terms of } L \text { of }
$$
degree $p$ and $q$.

$y_{t}$ is the time series, and $e_{t}$ is the random error at time period $t$, with $\mu$ is the mean of the model.

$d$ is the order of the difference operator.

$\varphi_{1}, \varphi_{2}, \cdots, \varphi_{p}$ and $\vartheta_{1}, \vartheta_{2}, \cdots, \vartheta_{q}$ are the parameters of autoregressive and moving average terms with order $p$ and $q$ respectively.

$L$ is the difference operator defined as $\Delta y_{t}=y_{t}-y_{t-1}=(1-L) y_{t}$.

\section{- $\operatorname{ARIMA}(0,1,0)$ Random walk model}

A random walk with or without drift presenting a constant, is regarded as an AR (1) process. The regression of $y_{t}$ on $y_{t-1}$ is estimated as follows:

$$
y_{t}=\rho y_{t-1}+e_{t}
$$

If $\rho=1$, the model is a random walk.

\section{- Random walk without drift:}

$$
y_{t}=y_{t-1}+e_{t}
$$

A random walk without drift is a procedure where the dependent variable can be estimated on a lagged period by itself together with an error term which is a white noise, known as random shock. The formula of a random walk without drift excludes the intercept. The mean is constant during time in a random walk 
without drift, whereas variance is increasing indefinitely in the course of time, featuring a non-stationary stochastic process (Gujarati \& Porter, 2008).

- Random walk with drift:

$$
y_{t}=\beta+y_{t-1}+e_{t}
$$

A random walk with drift is a process where the variable is dependent from its own lagged values and a random shock. However, the model which can estimate a random walk with drift consists of an intercept known as drift which is denoted as $\beta$. This parameter indicates if time series tend upwards or downwards, according to positive or negative sign of $\beta$. A random walk with drift is a non-stationary stochastic procedure where mean and variance increase in the course of time (Gujarati \& Porter, 2008).

If a time series $y_{t}$ is non-stationary, the simplest model is a random walk which can be considered as a limited case of an AR (1) model in which the autoregressive coefficient is equal to 1 meaning a series with infinitely slow mean reversion

Forecasting equation for this model can be written as follows:

$$
\hat{y}_{t}-y_{t-1}=\beta
$$

or

$$
\hat{y}_{t}=\beta+y_{t-1}
$$

where the constant is the average period-to-period change (the long run shift) on $y_{t}$. This model could be fit as regression model without a constant in which the first difference of $y_{t}$ is the dependent variable. Given that it consists only a non seasonal difference and a constant term, it is classified as ARIMA $(0,1,0)$ model without constant. A random walk model without drift could be an ARIMA $(0,1,0)$ model without constant. The ARIMA $(0,1,0)$ model is a non stationary time series, simply a random walk, a cumulative sum innovations or shocks. Considering that the expected value of an innovation is zero, the expected cumulative sum on period ahead is just the current value of cumulative sum. Thus, a forecasting is equal with the last observation. Meanwhile, a forecasting for a stationary time series will almost never be equal with the last observation.

\subsection{The Box-Jenkins Methodology}

Box-Jenkins procedure (Box \& Jenkins, 1976) in the time series analysis is a methodology in figuring out an ARIMA $(p, d, q)$ model or $\varphi(L) \Delta^{d} Y_{t}=\delta+\vartheta(L) \varepsilon_{t}$ which satisfactorily presents the stochastic procedure where the sample derived. The univariate Box-Jenkins methodology is purely a tool for forecasting and is used for short time forecasting. The Box-Jenkins approach consists of the following steps:

- Preparation of the data for a constant variance (series stationarity).

- Identification of the model.

- Estimation of the model.

- Diagnostic checking of the model. 


\subsection{Methods Exponential Smoothing (Holt-Winters Models)}

When data appear a random variation during time, smoothing methods can be used to reduce or eliminate the result of these variations. So, when we discuss about time series smoothing we refer to the reduction or elimination of the variance on this series. Exponential smoothing was proposed in the late 1950s by Brown (1959), Holt (1957) and Winters (1960) and is one of the most successful forecasting methods. Forecasting which is produced with the use of exponential smoothing methods, are weighted averages of past values, with the weights decaying exponentially as the observations expand. Exponential smoothing covers a wide range of methods, including some recent advances, such as the long run approaches of the united exponential smoothing and the linear Holt methods which continue to be of vital importance on this sector. Holt-Winters model is a method which also uses historical prices and its basic characteristic is the so-called "exponential smoothing".

\section{- Simple Exponential Smoothing-SES (One Parameter)}

The simplest exponential smoothing method is called Simple Exponential Smoothing-SES, and is the most suitable for short run forecasting. This method is suitable for forecasting without trend or seasonality. The model of simple exponential smoothing consists of two equations. A forecasting equation and a smoothing equation (level equation) for every component which is included on this method are provided. The model of simple exponential smoothing is as follows:

$$
\begin{aligned}
& \text { Forecasting function: } \hat{y}_{t+h \mid t}=L_{t} \\
& \text { Level function: } L_{t}=\alpha y_{t}+(1-\alpha) L_{t-1}
\end{aligned}
$$

where $L_{t}$ is the level or the smoothing of the series on time $t$. For $h=1$ it provides the estimated values, whereas for $t=T$ provides the actual forecasting beyond the model's data.

\section{- Double Exponential Smoothing (One Parameter)}

The double exponential smoothing or Holt method (Holt, 1957) is an extension of the simple exponential smoothing and it is used for data forecasting showing a linear trend. The model of double exponential consists of three equations, a forecasting equation and two smoothing equations (one for the level and one for the trend). The model of double exponential smoothing is given as follows:

$$
\begin{aligned}
& \text { Forecasting function: } \hat{y}_{t+h \mid t}=L_{t}+h b_{t} \\
& \text { Level function: } L_{t}=\alpha y_{t}+(1-\alpha)\left(L_{t-1}+b_{t-1}\right) \\
& \text { Trend function: } b_{t}=\beta\left(L_{t}-L_{t-1}\right)+(1-\beta) b_{t-1}
\end{aligned}
$$

where $L_{t}$ present the estimation of level series on time $t, b_{t}$ present the estimation of trend (slope) series on time $t, \alpha$ is the smoothing parameter for the level, $0 \leq \alpha \leq 1$ and $\beta$ is the smoothing parameter of trend $0 \leq \beta \leq 1$.

\section{- Holt-Winters-No Seasonal (Two Parameters)}

Holt-Winters method without seasonality is suitable for series with linear time 
trend and without seasonal variances. This method is similar with the double smoothing method as both of them create forecasting with linear trend but without seasonal component. While the double smoothing method uses one parameter, this method uses two. The Holt-Winters model without seasonality is presented in the following equations:

$$
\begin{aligned}
& \text { Level equation: } L_{t}=\alpha y_{t}+(1-\alpha)\left(L_{t-1}+b_{t-1}\right) \\
& \text { Trend equation: } b_{t}=\beta\left(L_{t}-L_{t-1}\right)+(1-\beta) b_{t-1} \\
& \text { Forecasting equation: } \hat{y}_{t+h \mid t}=L_{t}+h b_{t}
\end{aligned}
$$

The first equation computes the level at time $t$ as a weighted average of the last observation of time series $y_{t}$ and the level for forecasting. It is based on $L_{t-1}$ at $t-1$ period and on $b_{t-1}$ slope at time $t-1$. Slope expresses the linear increase of level, in a time unit, meaning that is represents the "discrete derivative" of level. The basic idea is that level moves though a straight line but due to shocks or implicit errors, deviates from the straight line. This is revealed by the fact that the last observation of time series $y_{t}$ is different from $L_{t-1}+b_{t-1}$ quantity. Consequently, the level during time $t$ should be adjusted from such a deviation. However, given that the implicit error should not be incorporated on the new value on level, we adopt the mean of $y_{t}$ and $L_{t-1}+b_{t-1}$, with a smoothing parameter $\alpha$, which determines the relative importance of the last observation and the previous one of time series, summarized by the values $L_{t-1}$ and $b_{t-1}$.

The second equation states a recursion for slope, which is evolving and adjusting during time, as it happens in level $L_{t}$. The slope value on time $t$ is a weighted mean of the previous value $b_{t-1}$ and the last observed slope, $L_{t}-L_{t-1}$. As far as the level is concerned, the reason that the weighted average is chosen is because the variances can compromise between the past time series and the most recent fluctuation.

Finally, the third equation refers to the way that a new observation carries on $h$ steps ahead in the future, based on past time series. In other words, it features the last level along with the last slope $h$ steps in the future.

\subsection{Forecasting}

One of the main reasons in the analysis of time series model is forecasting. Forecasting is distinguished into static and dynamic. Static forecasting, known as one-step ahead forecast, is always using the lagged values of the $Y$ time series for the forecasts. Dynamic forecasting on the other hand, known as the multi-step forecast, applies the real lagged variable $Y$ in order to estimate the first forecasting value. Then it uses the first forecasting value in order to forecast the second forecasting value and so on (Dritsaki, 2015).

If $s$ is the first sample observation to be forecasted, then we have the following equation:

$$
\hat{Y}_{s}=c(1)+c(2) Y_{s-1}
$$

where $Y_{s-1}$ is the real value of the last sample observation and $\hat{Y}_{s}$ is the first fo- 
recasted value. For the rest of the forecasted values we use the following equation:

$$
\hat{Y}_{s+k}=c(1)+c(2) Y_{s+k-1}
$$

where $\hat{Y}_{s+k-1}$ are the lagged forecasted values.

\subsection{Model Evaluation}

The precision of the forecasts depends on the forecasting error. Moreover, statistic measures are being used for this purpose, such as:

The Root Mean Square Error (RMSE)

$$
\operatorname{RMSE}=\sqrt{\frac{1}{n} \sum_{i=1}^{n}\left(Y_{i}-\hat{Y}_{i}\right)^{2}}
$$

where

$Y_{i}$ is the actual value.

$\hat{Y}_{i}$ is the prediction value.

The Mean Actual Error (MAE) is

$$
\text { MAE }=\frac{1}{n} \sum_{i=1}^{n}\left|Y_{i}-\hat{Y}_{i}\right|
$$

The Mean Actual Error measures the mean actual deviation of the prediction values from the actual ones.

The Mean Actual Percentage Error is (MAPE)

$$
\text { MAPE }=\frac{1}{n} \sum_{i=1}^{n}\left|\frac{Y_{i}-\hat{Y}_{i}}{Y_{i}}\right|=\frac{1}{n} \sum_{i=1}^{n}\left|e_{i}\right| \text { where } e_{i}=\left|Y_{i}-\hat{Y}_{i}\right|
$$

The Symmetric Mean Absolute Percentage Error (SMAPE) is

$$
\text { SMAPE }=\frac{1}{n} \sum_{i=1}^{n} \frac{\left|\hat{Y}_{i}-Y_{i}\right|}{\frac{\left|\hat{Y}_{i}\right|+\left|Y_{i}\right|}{2}} \times 100
$$

and the Theil's U statistics (Theil, 1961) is

$$
\begin{gathered}
U_{1}=\frac{\left[\frac{1}{n} \sum_{i=1}^{n}\left(Y_{i}-\hat{Y}_{i}\right)^{2}\right]^{1 / 2}}{\left[\frac{1}{n} \sum_{i=1}^{n} Y_{i}^{2}\right]^{1 / 2}+\left[\frac{1}{n} \sum_{i=1}^{n} \hat{Y}_{i}^{2}\right]^{1 / 2}} \\
U_{2}=\frac{\left[\sum_{i=1}^{n-1}\left(\frac{\hat{Y}_{i+1}-Y_{i+1}}{Y_{i}}\right)^{2}\right]^{1 / 2}}{\left[\sum_{i=1}^{n}\left(\frac{Y_{i+1}-Y_{i}}{Y_{i}}\right)^{2}\right]^{1 / 2}}
\end{gathered}
$$

We should mention that the smaller the values of the above indices, the better the fitting of the predicted time series to the actual ones, in other words, the better the forecasting ability of the sample. The values closer to zero in both $U_{1}$ and $U_{2}$ Theil statistics indicate a better forecasting performance of the samples under 
investigation. If both $U_{1}$ and $U_{2}$ Theil statistics are equal to zero then we are talking about a perfect prediction. Generally the $U_{1}$ Theil statistic lies between zero and one, whereas the $U_{2}$ Theil statistic has no boundaries.

\section{Data}

For the analysis of our paper, annual data are used for GDP per capita at 2015 reference levels (ECU/EUR) for all examined countries from 1990 until 2020. Based on this data, the ARIMA and Holt-Winters-no seasonal models are developed for each country and then are applied for forecasting per capita GDP. Annual data for GDP per capita are downloaded from the World Bank's Development Indicators. In Table 1, the descriptive statistics for GDP per capita for all examined countries are presented.

From the above table, Greece has the largest GDP per capita on average 15.006 euros. Slovenia follows with 14.074 euros on average, Croatia with 7.687 euros, Romania with 4.629 euros and Bulgaria has the smallest GDP per capita 3.816 euros. Slovenia has the highest standard deviation 5.58 meaning that GDP per capita expands on a large scale, whereas Bulgaria has the smallest standard deviation 2.532 and the values are close to the mean. Also, three countries namely Croatia, Greece and Slovenia present negative skewness. This means that there are remote values on GDP per capita that are smaller than average while Bulgaria and Romania have positive skewness meaning that the remote values on GDP

Table 1. Descriptive statistics GDP at 2015 reference levels per capita of population (ECU/EUR).

\begin{tabular}{cccccc}
\hline & BUL & CR & GR & ROM & SL \\
\hline Mean & 3.816129 & 7.687097 & 15.00645 & 4.629032 & 14.07419 \\
Median & 3.100000 & 8.500000 & 16.30000 & 3.700000 & 14.60000 \\
Maximum & 8.800000 & 13.30000 & 21.80000 & 11.50000 & 23.20000 \\
Minimum & 0.700000 & 1.700000 & 7.600000 & 0.400000 & 4.900000 \\
Std. Dev. & 2.532469 & 3.672941 & 4.112172 & 3.494109 & 5.588617 \\
Skewness & 0.476481 & -0.295932 & -0.245351 & 0.467181 & -0.204036 \\
Kurtosis & 1.892487 & 1.721240 & 2.077947 & 1.890012 & 1.818952 \\
Jarque-Bera & 2.757349 & 2.564644 & 1.409168 & 2.719095 & 2.016806 \\
Probability & 0.251912 & 0.277392 & 0.494314 & 0.256777 & 0.364801 \\
Sum & 118.3000 & 238.3000 & 465.2000 & 143.5000 & 436.3000 \\
Sum Sq. Dev & 192.4019 & 404.7148 & 507.2987 & 366.2639 & 936.9794 \\
Observations & 31 & 31 & 31 & 31 & 31 \\
\hline
\end{tabular}


per capita are higher than the average. All examined countries are platykyrtic (Pearson coefficient $<3$ ). Finally, data on GDP per capita in all countries follow normal distribution.

\section{Empirical Results}

- Time series plots

On the following figure, the graphs of GDP per capita for each country are featured.

From Figure 1 we can see that GDP per capita in four countries (except Greece) have an upward trend in a large time span until 2019 and afterwards a downfall because of COVID-19 pandemia. Nevertheless, focusing on the movement of GDP per capita for all countries we can argue that it is a random walk model.

- Estimation of linear series trend.

In the following diagram, the linear trend model and trend analysis plot for the examined countries are presented (Figure 2).

The results show that there is a linear trend of GDP per capita for the examined countries. So, the GDP per capita for all countries present a linear trend and is regarded as a random walk model.

\subsection{Testing for Stationarity}

In Table 2, the corresponding timing of the structural break of GDP per capita for each country is presented.

From the results of the above table we can point out that GDP per capita variable has a unit root in levels with one structural break. Afterwards, the variable becomes stationary in first differences with one structural break. The year is 2008 or 2009 for all countries, a year later after the financial crisis of 2007 affecting the banking and financial sector starting from USA.

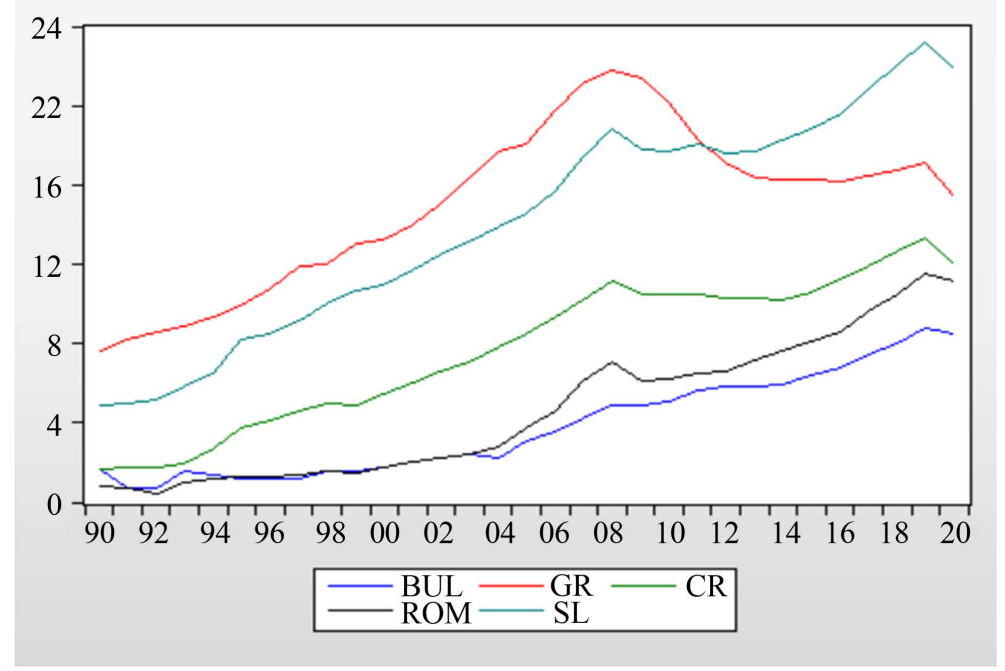

Figure 1. Time series plot of original series per capita GDP. 
Dependent Variable: BUL

Method. Least Squares

Sample: 19902020

Included observations: 31

\begin{tabular}{lrlll}
\hline \hline \multicolumn{1}{c}{ Variable } & Coefficient & Std. Error & t-Statistic & Prob. \\
\hline \hline \multicolumn{1}{c}{ C } & -0.206048 & 0.244405 & -0.843062 & 0.4061 \\
\multicolumn{1}{c}{ @TREND } & 0.268145 & 0.013995 & 19.16065 & 0.0000 \\
\hline \hline R-squared & 0.926792 & Mean dependent var & 3.816129 \\
Adjusted R-squared & 0.924267 & S. D. dependent var & 2.532469 \\
S. E. ofregression & 0.696924 & Akaike info criterion & 2.178061 \\
Sum squared resid & 14.08540 & Schwaz criterion & 2.270576 \\
Log likelihood & -31.75995 & Hannan-Quinn criter. & 2.208219 \\
F-statistic & 367.1304 & Durbin-Watson stat & 0.345768 \\
Prob (F-statistic) & 0.000000 & & & \\
& & & &
\end{tabular}

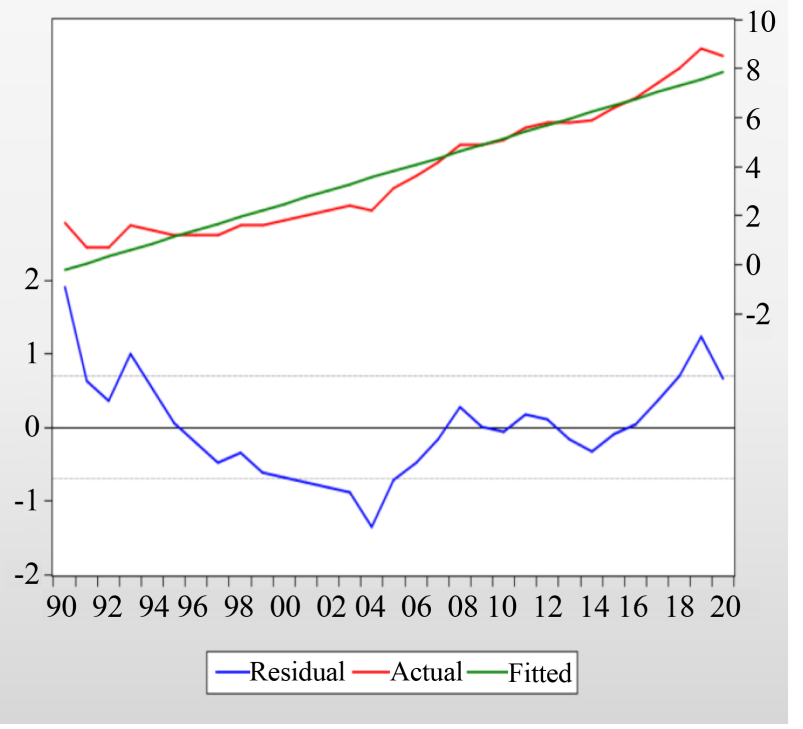

Dependent Variable: CR

Method: Least Squares

Sample: 19902020

Included observations: 31

\begin{tabular}{lclll}
\hline \hline \multicolumn{1}{c}{ Variable } & Coefficient & Std. Error & t-Statistic & Prob. \\
\hline \hline \multicolumn{1}{c}{ C } & 1.789315 & 0.300687 & 5.950745 & 0.0000 \\
\multicolumn{1}{c}{ @TREND } & 0.393185 & 0.017217 & 22.83663 & 0.0000 \\
\hline \hline R-squared & 0.947322 & Mean dependent var & 7.687097 \\
Adjusted R-squared & 0.945505 & S. D. dependent var & 3.672941 \\
S. E. ofregression & 0.857415 & Akaike info criterion & 2.592552 \\
Sum squared resid & 21.31967 & Schwaz criterion & 2.685068 \\
Log likelihood & -38.18456 & Hannan-Quinn criter. & 2.622710 \\
F-statistic & 521.5117 & Durbin-Watson stat & 0.344669 \\
Prob (F-statistic) & 0.00000 & & & \\
& & & & \\
& & & & \\
\end{tabular}

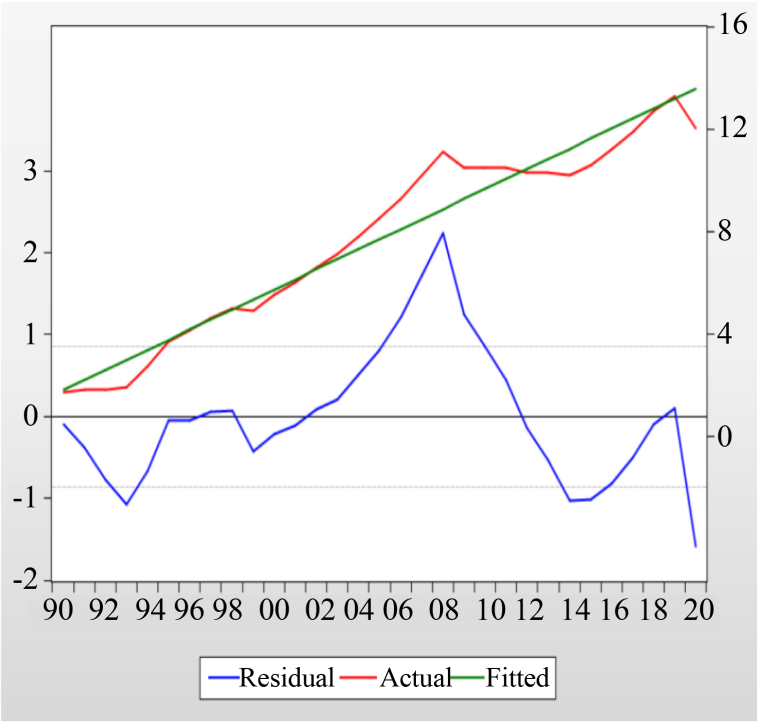

Dependent Variable: GR

Method: Least Squares

Sample: 19902020

Included observations: 31

\begin{tabular}{lllll}
\hline \hline \multicolumn{1}{c}{ Variable } & Coefficient & Std. Error & t-Statistic & Prob. \\
\hline \hline \multicolumn{1}{c}{ C } & 10.00141 & 0.990164 & 10.10076 & 0.0000 \\
\multicolumn{1}{c}{ @TREND } & 0.333669 & 0.056697 & 5.885172 & 0.0000 \\
\hline \hline R-squared & 0.544278 & Mean dependent var & 15.00645 \\
Adjusted R-squared & 0.528563 & S. D. dependent var & 4.112172 \\
S. E. ofregression & 2.823469 & Akaike info criterion & 4.976150 \\
Sum squared resid & 231.1873 & Schwaz criterion & 5.068666 \\
Log likelihood & -75.13033 & Hannan-Quinn criter. & 5.006308 \\
F-statistic & 34.63525 & Durbin-Watson stat & 0.100329 \\
Prob (F-statistic) & 0.000002 & & & \\
\hline
\end{tabular}

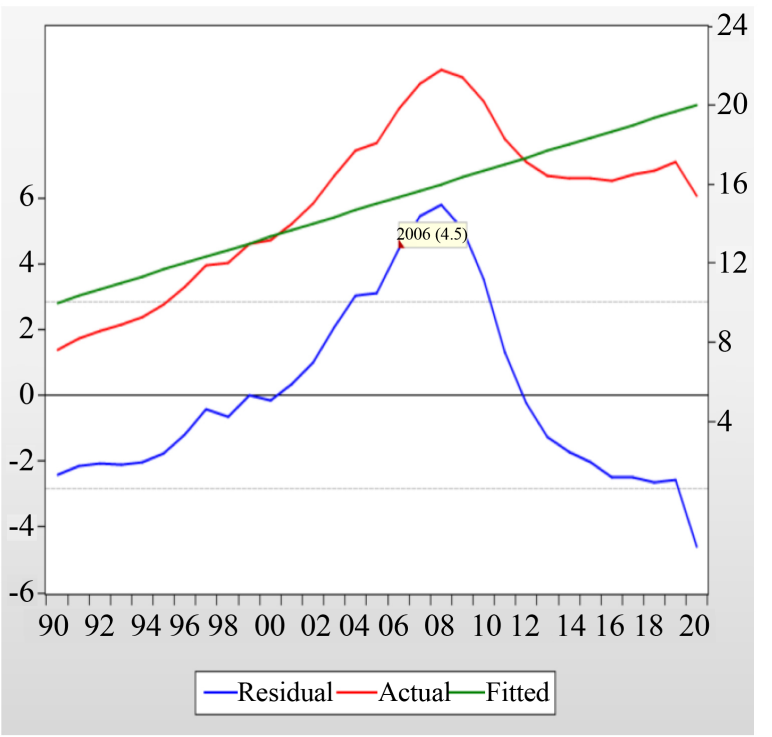


Dependent Variable: ROM

Method: Least Squares

Sample: 19902020

Included observations: 31

\begin{tabular}{lrlll}
\hline \hline \multicolumn{1}{c}{ Variable } & Coefficient & Std. Error & t-Statistic & Prob. \\
\hline \hline \multicolumn{1}{c}{ C } & -0.935484 & 0.325436 & -2.874558 & 0.0075 \\
\multicolumn{1}{c}{ @TREND } & 0.370968 & 0.018634 & 19.90769 & 0.0000 \\
\hline \hline R-squared & 0.931815 & Mean dependent var & 4.629032 \\
Adjusted R-squared & 0.929464 & S. D. dependent var & 3.494109 \\
S. E. ofregression & 0.927985 & Akaike info criterion & 2.750739 \\
Sum squared resid & 24.97355 & Schwaz criterion & 2.843255 \\
Log likelihood & -40.63646 & Hannan-Quinn criter. & 2.780897 \\
F-statistic & 396.3161 & Durbin-Watson stat & 0.296176 \\
Prob (F-statistic) & 0.000000 & & & \\
& & & &
\end{tabular}

Dependent Variable: SL

Method: Least Squares

Sample: 19902020

Included observations: 31

\begin{tabular}{cccccc}
\hline \hline Variable & Coefficient & Std. Error & t-Statistic & Prob. \\
\hline \hline C & 4.997984 & 0.350662 & 14.25298 & 0.0000 \\
@TREND & 0.605081 & 0.020079 & 30.13520 & 0.0000
\end{tabular}

\begin{tabular}{lcc}
\hline \hline R-squared & 0.969054 Mean dependent var & 14.07419 \\
Adjusted R-squared & 0.967987 S. D. dependent var & 5.588617 \\
S. E. ofregression & 0.999920 Akaike info criterion & 2.900057 \\
Sum squared resid & 28.99534 Schwaz criterion & 2.992573 \\
Log likelihood & -42.95089 Hannan-Quinn criter & 2.930215 \\
F-statistic & 908.1300 Durbin-Watson stat & 0.461831 \\
Prob (F-statistic) & 0.000000 &
\end{tabular}
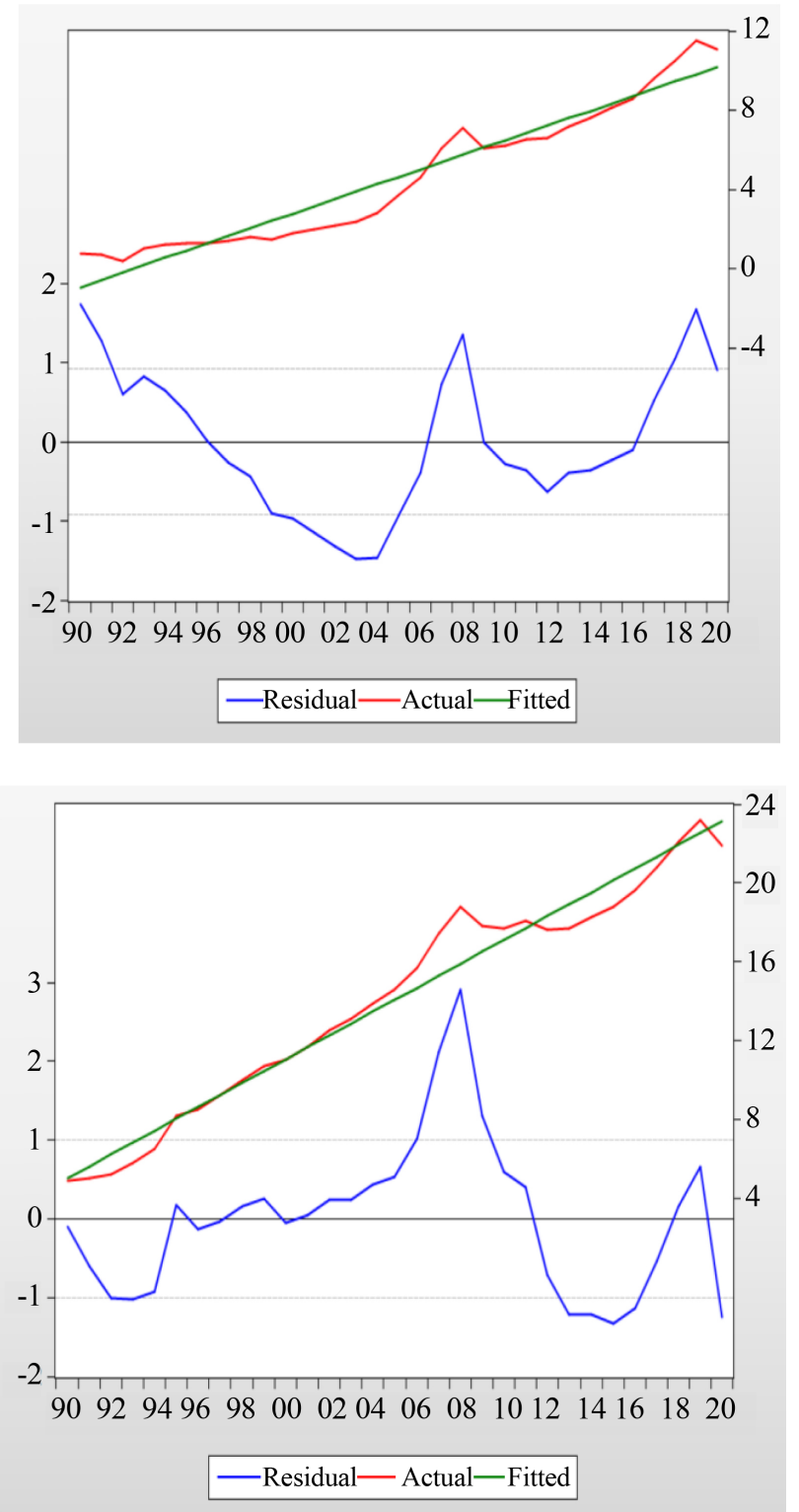

Figure 2. Linear trend model and trend analysis plot per capita GDP.

\subsection{Estimation and Diagnostic Tests of the Models}

From the moment that the models are ARIMA $(0,1,0)$ random walk models, the estimation will be employed using the ordinary least squares methodology. The diagnostic tests of the models consist of the specification model (Ramsey, 1969) RESET test, residuals' normality (Jarque \& Bera, 1980), residuals' autocorrelation (Breusch \& Godfrey, 1981), heteroscedasticity (White, 1980) and autoregressive conditional heteroscedasticity (ARCH model (Engle, 1982)). Table 3 features the results of all models' estimation.

The results from the above table indicate that coefficients' from all models are statistical significant in $1 \%$ level of significance. Diagnostic tests in most of the models and for all countries face slight problems, so we can proceed on with forecasting. 
Table 2. One endogenous structural break Zivot-Andrews unit root test.

\begin{tabular}{|c|c|c|c|c|c|c|}
\hline \multirow{2}{*}{$\begin{array}{l}\text { GDP per } \\
\text { capita }\end{array}$} & $\begin{array}{c}\text { Lag lengths } \\
{[\mathrm{k}]}\end{array}$ & t-statistics & Break & $\begin{array}{c}\text { Lag lengths } \\
{[\mathrm{k}]}\end{array}$ & t-statistics & Break \\
\hline & \multicolumn{3}{|c|}{ Level } & \multicolumn{3}{|c|}{ First differences } \\
\hline & \multicolumn{6}{|c|}{ Bulgaria } \\
\hline Intercept & - & - & - & {$[0]$} & $-5.76^{\star}$ & 2008 \\
\hline Trend & {$[0]$} & $-4.15^{\star \star \star}$ & 2002 & {$[0]$} & $-6.16^{\star}$ & 2009 \\
\hline \multirow[t]{2}{*}{ Both } & {$[0]$} & -4.17 & 2005 & {$[0]$} & $-6.06^{*}$ & 2009 \\
\hline & \multicolumn{6}{|c|}{ Croatia } \\
\hline Intercept & {$[1]$} & -2.64 & 2012 & {$[0]$} & -3.81 & 2009 \\
\hline Trend & {$[1]$} & -4.09 & 2009 & {$[0]$} & $-6.12^{*}$ & 2008 \\
\hline \multirow[t]{2}{*}{ Both } & {$[1]$} & -4.22 & 2006 & {$[0]$} & $-5.94^{\star}$ & 2009 \\
\hline & \multicolumn{6}{|c|}{ Greece } \\
\hline Intercept & {$[1]$} & -2.34 & 2010 & {$[2]$} & $-4.61^{\star * *}$ & 2008 \\
\hline Trend & {$[1]$} & -3.25 & 2004 & {$[2]$} & $-4.56^{\star *}$ & 2008 \\
\hline \multirow[t]{2}{*}{ Both } & {$[1]$} & -4.13 & 2006 & {$[2]$} & $-5.95^{\star}$ & 2008 \\
\hline & \multicolumn{6}{|c|}{ Romania } \\
\hline Intercept & - & - & - & {$[0]$} & $-5.61^{\star}$ & 2009 \\
\hline Trend & {$[1]$} & -3.64 & 2002 & {$[0]$} & $-4.83^{\star *}$ & 2007 \\
\hline \multirow[t]{2}{*}{ Both } & {$[1]$} & -3.79 & 2005 & {$[0]$} & $-5.53^{\star}$ & 2009 \\
\hline & \multicolumn{6}{|c|}{ Slovenia } \\
\hline Intercept & {$[1]$} & -4.50 & 2012 & {$[0]$} & $-4.73^{\star * *}$ & 2009 \\
\hline Trend & [1] & -3.90 & 2008 & [0] & $-4.91^{\star *}$ & 2009 \\
\hline Both & [1] & $-4.85^{\star * *}$ & 2012 & {$[0]$} & $-4.87^{\star * *}$ & 2009 \\
\hline
\end{tabular}

Notes: $1 .{ }^{*}{ }^{* *}$ and ${ }^{\star * *}$ show significant at $1 \%, 5 \%$ and $10 \%$ levels respectively. 2 . Critical values intercept: $-5.34(1 \%),-4.93(5 \%),-4.58(10 \%)$, trend: $-4.80(1 \%),-4.42(5 \%)$, -4.11 (10\%), both: $-5.57(1 \%),-5.08(5 \%),-4.82(10 \%)$. 3. In brackets we note down the time lags for the corresponding equations. 4 . The optimal lag length is selected using $t$-sig, with the maximum lag set to 4 .

Table 3. Estimation and diagnostic checking of the models ARIMA $(0,1,0)$.

\begin{tabular}{cccccc}
\hline & $\begin{array}{c}\text { BUL } \\
\text { ARIMA } \\
(0,1,0)\end{array}$ & $\begin{array}{c}\text { CR } \\
\text { ARIMA } \\
(0,1,0)\end{array}$ & $\begin{array}{c}\text { GR } \\
\text { ARIMA } \\
(0,1,0)\end{array}$ & $\begin{array}{c}\text { ROM } \\
\text { ARIMA } \\
(0,1,0)\end{array}$ & $\begin{array}{c}\text { SL } \\
\text { ARIMA } \\
(0,1,0)\end{array}$ \\
\hline C & - & $0.588^{*}$ & $1.436^{* *}$ & - & $0.859^{*}$ \\
y - 1 & $1.055^{*}$ & $0.967^{*}$ & $0.921^{*}$ & $1.061^{*}$ & $0.978^{*}$ \\
& Diagnostic Checking of the Model & & \\
RESET F (1, 27) & 0.905 & $5.093^{* *}$ & 1.055 & 2.829 & 2.147 \\
J-B X ${ }^{2}(2)$ & 2.876 & 3.897 & 0.118 & $9.605^{* * *}$ & 1.496 \\
\hline
\end{tabular}


Continued

\begin{tabular}{|c|c|c|c|c|c|}
\hline B-G $\mathrm{X}^{2}(2)$ & 1.779 & 3.334 & $12.671^{\star}$ & 2.102 & 2.511 \\
\hline White $\mathrm{X}^{2}(2)$ & 0.009 & $12.267^{\star}$ & $6.495^{\star \star}$ & 2.399 & $11.438^{*}$ \\
\hline $\mathrm{ARCH} \mathrm{X}^{2}(1)$ & 0.149 & 0.722 & 2.119 & 0.881 & 1.810 \\
\hline
\end{tabular}

Notes: $1 .{ }^{*},{ }^{* *}$ and ${ }^{* * *}$ show significant at $1 \%, 5 \%$ and $10 \%$ levels respectively.

\subsection{Holt-Winters Forecasting Results}

Table 4 presents the forecasting accuracy of the three exponential smoothing models which are computed on the basis of statistics measures.

The results in Table 4, with all forecasting indices, indicate that Holt-Winters model is the best for all countries in obtaining a much accurate short-term out-of-sample of GDP per capita. So, this model can be used for forecasting.

Table 5 presents the smoothing parameters, the level, trend and the sum of squares residuals for the non seasonal Holt-Winters model on the examined countries. The smoothing parameters, alpha and beta, are used for the components estimation on the level and on trend. Smoothing parameters get values between 0 and 1 . Values near zero denote a relatively little weight on recent observations when making forecasts of future values. Conversely, values closer to 1 denote that a great weight falls on the observations of the distant past in order to obtain future forecast values.

\subsection{Forecasting Accuracy: Seasonal-ARIMA vs. Holt-Winters}

Table 6 presents the indices of forecasting accuracy on ARIMA $(0,1,0)$ random walk model and Holt-Winters-non seasonal for the examined countries. For evaluation sample we define the period 2020-2024 giving four years prediction and as training sample for the least-square, mean square error methods and MSE ranks we define the years 2015-2019.

From Table 6, the out-of-sample forecast performances of ARIMA models and Holt-Winters model were ranked for all countries using accuracy measure statistics: RMSE, MAE, MAPE, SMAPE, and Theil $U_{1}$. The ARIMA model showed the smallest forecasting errors in four out of five examined countries whereas for Romania, the Holt-Winters model of non seasonal smoothing was the most suitable for obtaining a much accurate short-term out-of-sample GDP per capita. Forecasting evaluation criteria denote that composite forecasts are superior compared with the individual models.

Table 7 presents the forecasted values for ARIMA (Bulgaria, Croatia, Greece Slovenia) and Holt-Winters (Romania) models for four periods ahead starting from 2021 until 2024.

The forecasted values in all countries for GDP per capita and the corresponding models are presented in Figure 3.

The results in Figure 3 show an increase of forecasted values on GDP per capita for four countries (Bulgaria, Croatia, Romania and Slovenia) for the years 2021 until 2024. Specifically, Bulgaria will have the largest increase on GDP per 
Table 4. Forecasting accuracy measure statistics of the three exponential smoothing models.

\begin{tabular}{|c|c|c|c|c|c|c|}
\hline $\begin{array}{c}\text { Forecasting } \\
\text { Models }\end{array}$ & RMSE & MAE & MAPE & SMAPE & $\begin{array}{c}\text { Theil } \\
U_{1}\end{array}$ & $\begin{array}{c}\text { Theil } \\
U_{2}\end{array}$ \\
\hline & \multicolumn{6}{|c|}{ Bulgaria } \\
\hline Single & 0.453 & 0.343 & 14.082 & 13.297 & 0.051 & 1.000 \\
\hline Double & 0.419 & 0.350 & 16.964 & 15.825 & 0.046 & 0.903 \\
\hline \multirow[t]{2}{*}{ H-W } & 0.397 & 0.295 & 13.838 & 12.524 & 0.043 & 1.005 \\
\hline & \multicolumn{6}{|c|}{ Croatia } \\
\hline Single & 0.788 & 0.574 & 12.660 & 10.593 & 0.047 & 1.000 \\
\hline Double & 0.543 & 0.345 & 7.368 & 7.371 & 0.031 & 1.014 \\
\hline \multirow[t]{2}{*}{ H-W } & 0.495 & 0.363 & 6.065 & 5.877 & 0.028 & 0.779 \\
\hline & \multicolumn{6}{|c|}{ Greece } \\
\hline Single & 1.216 & 0.870 & 6.740 & 6.358 & 0.039 & 1.000 \\
\hline Double & 0.700 & 0.553 & 3.820 & 3.788 & 0.022 & 0.754 \\
\hline \multirow[t]{2}{*}{ H-W } & 0.673 & 0.504 & 3.226 & 3.193 & 0.021 & 0.696 \\
\hline & \multicolumn{6}{|c|}{ Romania } \\
\hline Single & 0.612 & 0.481 & 16.970 & 16.534 & 0.054 & 0.999 \\
\hline Double & 0.545 & 0.344 & 15.759 & 15.107 & 0.047 & 1.080 \\
\hline \multirow[t]{2}{*}{ H-W } & 0.495 & 0.349 & 12.983 & 11.880 & 0.043 & 0.870 \\
\hline & \multicolumn{6}{|c|}{ Slovenia } \\
\hline Single & 1.184 & 0.881 & 8.527 & 7.805 & 0.039 & 1.000 \\
\hline Double & 0.764 & 0.517 & 4.306 & 4.271 & 0.025 & 0.800 \\
\hline H-W & 0.660 & 0.455 & 3.322 & 3.294 & 0.021 & 0.670 \\
\hline
\end{tabular}

H-W: Holt-Winters no seasonal.

Table 5. Smoothing parameters with coefficients for level and trend (Holt-Winters-no seasonal).

\begin{tabular}{cccccc}
\hline & alpha & beta & SSR & L & b \\
\hline Bulgaria & 1.000 & 0.100 & 4.886 & 8.500 & 0.308 \\
Croatia & 1.000 & 0.020 & 7.603 & 12.000 & 0.394 \\
Greece & 0.940 & 1.000 & 14.053 & 15.524 & -1.565 \\
Romania & 1.000 & 0.080 & 7.622 & 11.100 & 0.412 \\
Slovenia & 1.000 & 0.000 & 13.538 & 21.900 & 0.646 \\
\hline
\end{tabular}

SSR: Sum of Squared Residuals; L: Level component; B: Trend component. 
Table 6. Forecast evaluation of individual models and composite forecasts.

\begin{tabular}{|c|c|c|c|c|c|}
\hline Forecast & RMSE & MAE & MAPE & SMAPE & Theil $U_{1}$ \\
\hline & & & Bulgaria & & \\
\hline Holt-Winters & 0.676469 & 0.676469 & 7.958460 & 7.653894 & 0.038269 \\
\hline ARIMA & 0.001111 & 0.001111 & 0.013067 & 0.013068 & $6.53 \mathrm{E}-05$ \\
\hline Simple mean & 0.337679 & 0.337679 & 3.972696 & 3.895322 & 0.019477 \\
\hline Simple Median & 0.337679 & 0.337679 & 3.972696 & 3.895322 & 0.019477 \\
\hline Least-squares & 0.340109 & 0.340109 & 4.001279 & 3.922798 & 0.019614 \\
\hline Mean squares error & 0.393701 & 0.393701 & 4.631778 & 4.526939 & 0.022635 \\
\hline \multirow[t]{2}{*}{ MSE ranks } & 0.450609 & 0.450609 & 5.301284 & 5.164394 & 0.025822 \\
\hline & & & Croatia & & \\
\hline Holt-Winters & 1.729278 & 1.729278 & 14.41065 & 13.44211 & 0.067211 \\
\hline ARIMA & 0.017380 & 0.017380 & 0.144831 & 0.144726 & 0.000724 \\
\hline Simple mean & 0.873329 & 0.873329 & 7.277742 & 7.022213 & 0.035111 \\
\hline Simple Median & 0.873329 & 0.873329 & 7.277742 & 7.022213 & 0.035111 \\
\hline Least-squares & 0.197213 & 0.197213 & 1.643445 & 1.630050 & 0.008150 \\
\hline Mean squares error & 1.605460 & 1.605460 & 13.37883 & 12.53998 & 0.062700 \\
\hline \multirow[t]{2}{*}{ MSE ranks } & 1.158646 & 1.158646 & 9.655379 & 9.210715 & 0.046054 \\
\hline & & & Greece & & \\
\hline Holt-Winters & 2.076546 & 2.076546 & 13.48407 & 12.63239 & 0.063162 \\
\hline ARIMA & 1.984547 & 1.984547 & 12.88667 & 12.10660 & 0.060533 \\
\hline Simple mean & 2.030547 & 2.030547 & 13.18537 & 12.36986 & 0.061849 \\
\hline Simple Median & 2.030547 & 2.030547 & 13.18537 & 12.36986 & 0.061849 \\
\hline Least-squares & 1.999030 & 1.999030 & 12.98072 & 12.18957 & 0.060948 \\
\hline Mean squares error & 2.066903 & 2.066903 & 13.42145 & 12.57741 & 0.062887 \\
\hline \multirow[t]{2}{*}{ MSE ranks } & 2.045880 & 2.045880 & 13.28493 & 12.45745 & 0.062287 \\
\hline & & & Romania & & \\
\hline Holt-Winters & 0.883371 & 0.883371 & 7.958298 & 7.653744 & 0.038269 \\
\hline ARIMA & 0.891687 & 0.891687 & 8.033214 & 7.723011 & 0.038625 \\
\hline Simple mean & 0.887529 & 0.887529 & 7.995756 & 7.688384 & 0.038442 \\
\hline Simple Median & 0.887529 & 0.887529 & 7.995756 & 7.688384 & 0.038442 \\
\hline Least-squares & 0.889367 & 0.889367 & 8.012311 & 7.703690 & 0.038518 \\
\hline Mean squares error & 0.885227 & 0.885227 & 7.975022 & 7.669211 & 0.038346 \\
\hline \multirow[t]{2}{*}{ MSE ranks } & 0.886143 & 0.886143 & 7.983270 & 7.676839 & 0.038384 \\
\hline & & & Slovenia & & \\
\hline Holt-Winters & 1.298899 & 1.298899 & 5.931044 & 5.760224 & 0.028801 \\
\hline
\end{tabular}




\section{Continued}

\begin{tabular}{cccccc}
\hline ARIMA & $\mathbf{0 . 0 9 7 9 1 2}$ & $\mathbf{0 . 0 9 7 9 1 2}$ & $\mathbf{0 . 4 4 7 0 8 7}$ & $\mathbf{0 . 4 4 8 0 8 8}$ & $\mathbf{0 . 0 0 2 2 4 0}$ \\
Simple mean & 0.600493 & 0.600493 & 2.741979 & 2.704895 & 0.031524 \\
Simple Median & 0.600493 & 0.600493 & 2.741979 & 2.704895 & 0.031524 \\
Least-squares & 0.190806 & 0.190806 & 0.871261 & 0.867482 & 0.004337 \\
Mean squares error & 0.624859 & 0.624859 & 2.853237 & 2.813105 & 0.014066 \\
MSE ranks & 0.833295 & 0.833295 & 3.805001 & 3.733962 & 0.018670 \\
\hline
\end{tabular}

Table 7. Forecasted values for 4 periods ahead.

\begin{tabular}{|c|c|c|c|}
\hline Period & Year & ARIMA & Holt-Winters \\
\hline \multicolumn{4}{|c|}{ Bulgaria } \\
\hline 1 & 2021 & 8.967 & 9.114 \\
\hline 2 & 2022 & 9.461 & 9.275 \\
\hline 3 & 2023 & 9.982 & 9.495 \\
\hline 4 & 2024 & 10.532 & 9.627 \\
\hline \multicolumn{4}{|c|}{ Croatia } \\
\hline 1 & 2021 & 12.215 & 12.394 \\
\hline 2 & 2022 & 12.406 & 12.789 \\
\hline 3 & 2023 & 12.591 & 13.184 \\
\hline 4 & 2024 & 12.770 & 13.578 \\
\hline \multicolumn{4}{|c|}{ Greece } \\
\hline 1 & 2021 & 17.456 & 13.959 \\
\hline 2 & 2022 & 17.523 & 12.394 \\
\hline 3 & 2023 & 17.585 & 10.829 \\
\hline 4 & 2024 & 17.641 & 9.264 \\
\hline \multicolumn{4}{|c|}{ Romania } \\
\hline 1 & 2021 & 12.578 & 11.512 \\
\hline 2 & 2022 & 13.183 & 11.925 \\
\hline 3 & 2023 & 13.808 & 12.338 \\
\hline 4 & 2024 & 14.453 & 12.750 \\
\hline \multicolumn{4}{|c|}{ Slovenia } \\
\hline 1 & 2021 & 22.199 & 22.546 \\
\hline 2 & 2022 & 22.588 & 23.193 \\
\hline 3 & 2023 & 22.969 & 23.840 \\
\hline 4 & 2024 & 23.341 & 24.486 \\
\hline
\end{tabular}


Forecast Comparison Graph

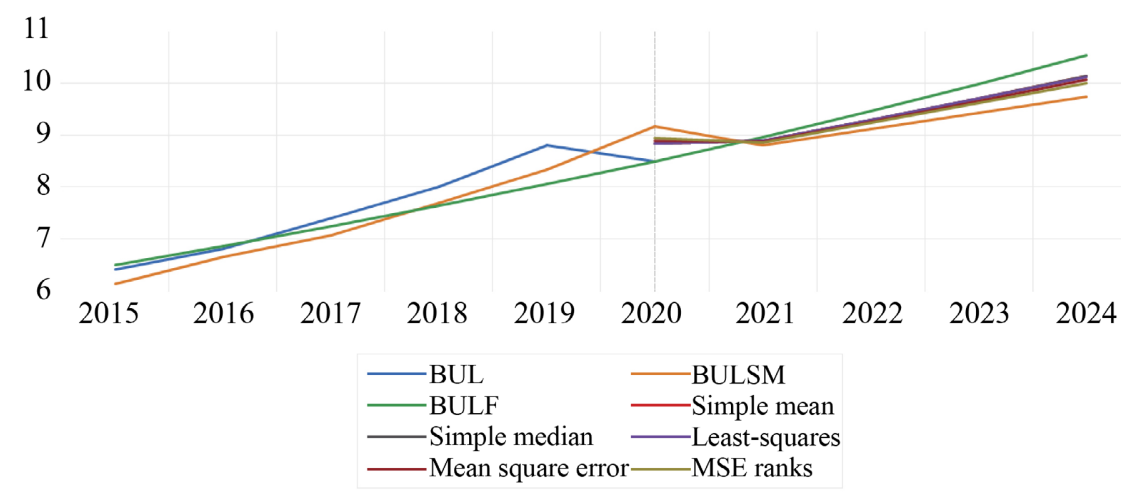

Forecast Comparison Graph

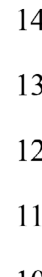

14

13

12

11

10

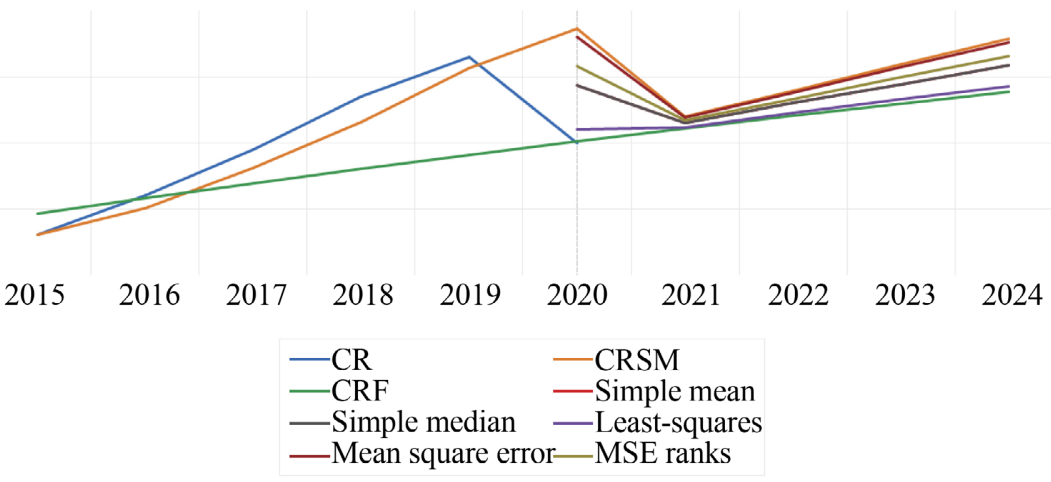

Forecast Comparison Graph

18

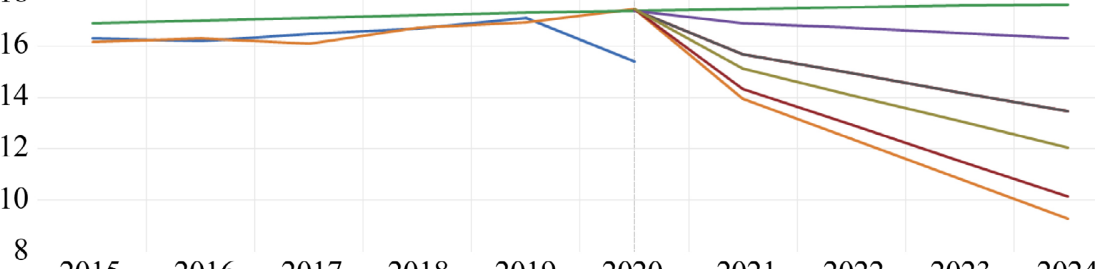

$\begin{array}{llllllllll}2015 & 2016 & 2017 & 2018 & 2019 & 2020 & 2021 & 2022 & 2023 & 2024\end{array}$

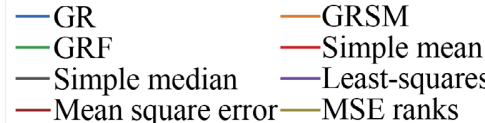

Forecast Comparison Graph

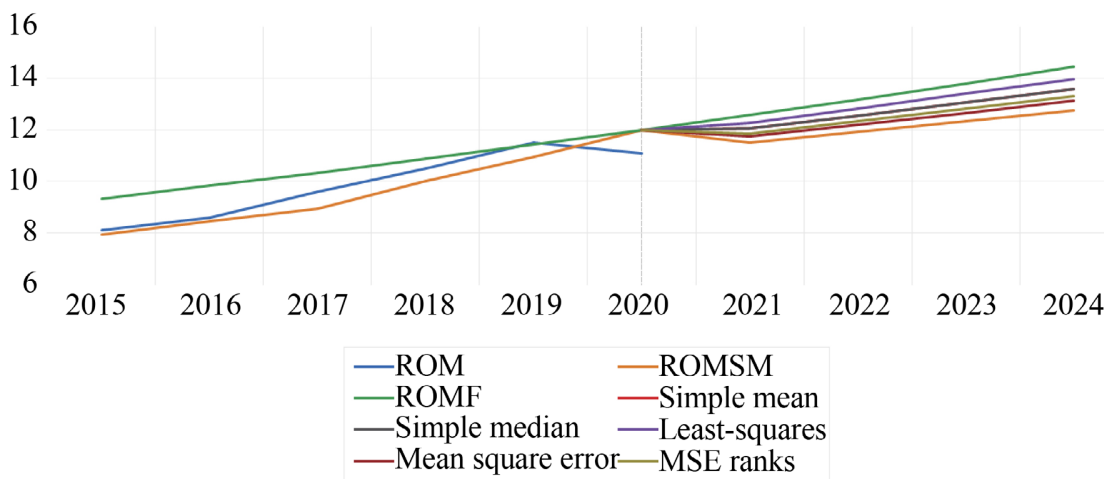




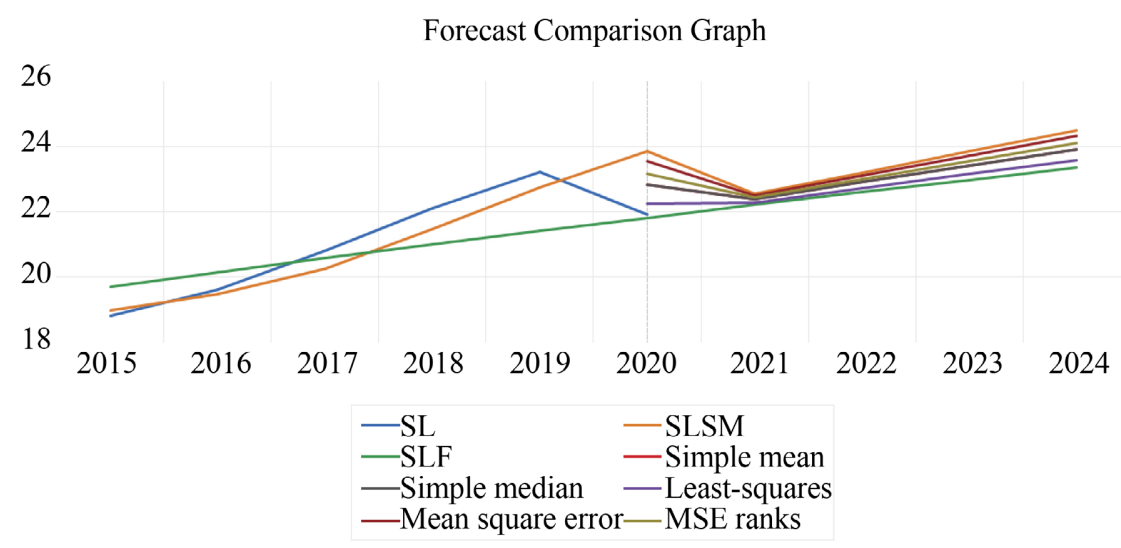

Figure 3. Forecasts from models for 4 periods ahead.

capita for the next four years and Romania will follow. Croatia and Slovenia seems from Figure 3 to have the same increase rates on GDP per capita. Greece is the only country which will have the smallest increase on GDP per capita for the forecasted years (in green colour). The fact that Greek economy is affected by the global financial crisis, the Greek debt crisis and pandemia resulted in the shrinkage of GDP per capita which will continue in the years ahead.

The forecasted values of GDP per capita in percentages for the following years are showed in Table 8.

From Table 8, it seems that the most important percentage increase of GDP per capita in the next four years is found in Bulgaria and the lowest increase in Greece.

\section{Discussion}

The significance of per capita GDP as a measure of economic growth could be examined in three different aspects. First of all, per capita GDP reflects the magnitude of economic growth in industrial countries. Second, in order to achieve a fair measurement of the GDP per capita, the individual income should not differ from one country to another. Therefore, countries that emphasize improving per capita income should also pay attention to social justice and equality. Third, it has been proved that per capita GDP relates to the level of social stability in a country (Zhang, 2013).

Given the importance of GDP per capita as a measure of economic growth, its forecast is a useful tool for conducting economic policy. The future is uncertain and forecasting the future is thus inherently difficult. Those responsible for policy-making decisions need to understand the economic condition of a country in order to make the best possible policy decisions. Given that GDP is considered a very important index for every government, its forecast could become a very useful tool for policymakers not only in the case of delivering an economic development plan but also dealing with possible recessions in advance. These decisions are made frequently under uncertainty not only as far as future economic conditions are concerned, but also under the current economic situation. Based 
Table 8. The forecasting results of ARIMA H-W models from 2021 to 2024.

\begin{tabular}{cccccc}
\hline & BUL & CR & GR & ROM (H-W) & SL \\
\hline $2020-2021$ & $5.41 \%$ & $1.79 \%$ & $1.47 \%$ & $3.71 \%$ & $1.37 \%$ \\
$2021-2022$ & $5.51 \%$ & $1.56 \%$ & $0.38 \%$ & $3.59 \%$ & $1.75 \%$ \\
$2022-2023$ & $5.50 \%$ & $1.49 \%$ & $0.36 \%$ & $3.46 \%$ & $1.67 \%$ \\
$2023-2024$ & $5.49 \%$ & $1.42 \%$ & $0.32 \%$ & $3.34 \%$ & $1.62 \%$ \\
\hline
\end{tabular}

on the fact that basic macroeconomic aggregates are published with a delay and are subject to frequent revisions, central banks have created forecasting models in order to mitigate those uncertainties and obtain an exact indication of the economic situation.

\section{Summary and Conclusion}

The current paper aims at forecasting the GDP per capita for the period between 2021-2024 in the case of Balkan countries which are members of the EU. For our analysis, we have used annual data for the GDP per capita in 2015 (ECU/EUR) as a base case for all examined countries from 1990 until 2020. In that framework, Box-Jenkins and Holt-Winters methodologies have been developed which are considered as dynamic models and are part of the Bayesian approach. The tests applied to the data showed that for all countries there is a linear trend, meaning there is a random walk model.

Due to the fact that the examined period of the paper consists of the world evolutions which shook many economies both with the 2007 recession as well as the COVID-19 in 2020, it was considered most appropriate to employ the $\mathrm{Zi}$ vot-Andrew test for unit root which contains these structural breaks. For all examined countries Zivot-Andrews test showed that data from all countries present a unit root at the first level and become stationary at their first differences, with the structural changes to be presented either in 2008 or 2009. In other words, the worldwide crisis of 2007 in the financial and banking sector of the USA affected Balkan countries one or two years later. Box-Jenkins methodology showed that ARIMA $(0,1,0)$ is the best fit for the model for all countries under consideration. Also, all diagnostic tests performed in the countries under examination did not present any issues. When using the Holt-Winters methodology, we used three exponential smoothing models to ensure the accuracy of the predictions which were calculated based on the RMSE, MAE, MAPE, SMAPE, Theil $U_{1}$, and Theil $U_{2}$ statistics. All statistics showed that Holt-Winters model is the most appropriate for all Balkan countries under examination. Hence, in order to forecast the per capita GDP of the Balkan countries, we used the ARIMA $(0,1,0)$ and Holt-Winters models as the most appropriate.

Computing RMSE, MAE, MAPE, SMAPE criteria and Theil's $U$ statistics, seems that ARIMA model is the optimum forecasting model and fits performance for the analyzed period in four out of five countries, incorporating GDP 
per capita significantly whereas, for Romania, the Holt-Winters model of nonseasonal smoothing is the most suitable.

Finally, the results of the analysis showed an increase in the predicted prices of the GDP per capita for all countries between 2021 and 2024 for both models under examination. The largest GDP per capita increase for this period was detected in Bulgaria and was more than 5\% for all years, while for the case of Greece it was the lowest. While both models provided predictions with great accuracy, the unexpected drop of the GDP per capita in all countries during the pandemic period of 2020 seems to have affected Greece because of the touristic product.

In addition, we should highlight that the sudden COVID-19 outburst, had a huge impact on the world economy, disturbing the economic activity of every country, corporate income as well as household income. Pandemia drove many countries to suspension, closing down business activity. As a result, GDP per capita had a prompt decline in all countries and also Balkan countries. Specifically, the decrease of GDP per capita in Bulgaria was 3.41\%, in Croatia 9.77\%, in Greece 9.94\%, in Romania 3.48\% and in Slovenia 5.6\% in 2020. However, the results of the paper show an increase in the forecasted values on GDP per capita for all examined countries from 2021 until 2024.

The forecasting models have been created based on time series regression, although in recent years progress in forecasting macroeconomic variables using neural networks and machine learning algorithms, has been occurred. Neural networks and ML algorithms though require access to big data set in order to produce sufficient results, to understand complex patterns and relationships between variables. Thus, the current paper uses Box-Jenkins and Holt-Winters methodologies which can use a small number of data, as the most appropriate for forecasting GDP increase.

\section{Conflicts of Interest}

The authors declare no conflicts of interest regarding the publication of this paper.

\section{References}

Box, G. E. P., \& Jenkins, G. M. (1976). Time Series Analysis. Forecasting and Control. Holden-Day.

Breusch, T. S., \& Godfrey, L. G. (1981). A Review of Recent Work on Testing for Autocorrelation in Dynamic Simultaneous Models. In D. Currie, R. Nobay, \& D. Peel, (Eds.), Macroeconomic Analysis: Essays in Macroeconomics and Econometrics (pp. 63-105). Croom Helm.

Brown, R. G. (1959). Statistical Forecasting for Inventory Control. McGraw Hill.

da Costa, K. V. S., da Silva, F. L. C., \& da Silva Cordeiro Coelho, J. (2020). Forecasting Quarterly Brazilian GDP: Univariate Models Approach. ArXiv: 2010.13259.

Dong, Z. S., \& Zhu, G. S. (2014). A Modified Exponential Smoothing Model for Forecasting per Capita GDP in Yunnan Minority Area. Applied Mechanics and Materials, 
599-601, 2074-2078. https://doi.org/10.4028/www.scientific.net/AMM.599-601.2074

Dritsaki, C. (2015). Forecasting Real GDP Rate through Econometric Models: An Empirical Study from Greece. Journal of International Business and Economics, 3, 13-19. https://doi.org/10.15640/jibe.v3n1a2

Dritsaki, M., \& Dritsaki, C. (2020). Forecasting European Union $\mathrm{CO}_{2}$ Emissions Using Autoregressive Integrated Moving Average-Autoregressive Conditional Heteroscedasticity Models. International Journal of Energy Economics and Policy, 10, 411-423. https://doi.org/10.32479/ijeep.9186

Eissa, N. (2020). Forecasting the GDP per Capita for Egypt and Saudi Arabia Using ARIMA Models. Research in World Economy, 11, 247-258.

Engle, R. F. (1982). Autoregressive Conditional Heteroskedasticity with Estimates of United Kingdom Inflation. Econometrica, 50, 987-1007. https://doi.org/10.2307/1912773

Galadima, M. D. (2016). Per Capita Income Prediction Using ARIMA Models (A Case Study of Nigeria). Sokoto Journal of Management Studies, 11, 382-398.

Gujarati, D. N., \& Porter, D. C. (2008). Basic Econometrics (5th ed.). McGraw Hill.

Holt, C. E. (1957). Forecasting Seasonals and Trends by Exponentially Weighted Averages (O.N.R. Memorandum No. 52). Carnegie Institute of Technology.

Jarque, C. M., \& Bera A. K. (1980). Efficient Tests for Normality, Homoscedasticity and Serial Independence of Regression Residuals. Economics Letters, 6, 255-259. https://doi.org/10.1016/0165-1765(80)90024-5

Makridakis, S., Andersen, A., Carbone, R., Fildes, R., Hibon, M., Lewandowski, R., Newton, J., Parzen, E., \& Winkler, R. (1982). The Accuracy of Extrapolation (Time Series) Methods: Results of a Forecasting Competition. Journal of Forecasting, 1, 111-153. https://doi.org/10.1002/for.3980010202

Makridakis, S., Wheelwright, S. C., \& Hyndman, R. J. (1998). Forecasting: Methods and Applications. John Wiley \& Sons. Inc.

Mourougane, A. (2006). Forecasting Monthly GDP for Canada. OECD Economics Department Working Paper No. 515.

Nyoni, T., \& Muchingami, L. (2019). Modeling and Forecasting Botswana's Growth Domestic Product (GDP) per Capita. MPRA Paper No. 93987.

Oral, I. O. (2019). Comparison of the Winters' Seasonality Exponential Smoothing Method with the Pegels' Classification: Forecasting of Turkey's Economic Growth Rates. Anadolu University Journal of Social Sciences, 19, 275-294.

Ramsey, J. B. (1969). Tests for Specification Errors in Classical Linear Least Squares Regression Analysis. Journal of the Royal Statistical Society Series B, 31, 350-371. https://doi.org/10.1111/j.2517-6161.1969.tb00796.x

Samimi, A. J., Shirazi, B., \& Fazlollahtabar, H. (2007). A Comparison between Time Series, Exponential Smoothing, and Neural Network Methods to Forecast GDP of Iran. Iranian Economic Review, 12, 19-35.

Sédillot, F., \& Pain, N. (2003). Indicator Models of Real GDP Growth in Selected OECD Countries. OECD Economics Department Working Paper No. 364.

Theil, H. (1961). Economic Forecasts and Policy. North-Holland Publishing Company.

Uwimana, A., Bi, X. C., \& Zhang, S. G. (2018). Modeling and Forecasting Africa's GDP with Time Series. International Journal of Scientific and Research Publications, 8, 41-46. https://doi.org/10.29322/IJSRP.8.4.2018.p7608

Wei, N., Bian, K. J., \& Yuan, Z. F. (2010). Analyze and Forecast the GDP of Shaanxi 
Province Based on the ARIMA Model. Journal of Asian Agricultural Research, 2, 34-41.

White, H. (1980). A Heteroskedasticity-Consistent Covariance Matrix Estimator and a Direct Test for Heteroskedasticity. Econometrica, 48, 817-838. https://doi.org/10.2307/1912934

Winters, P. R. (1960). Forecasting Sales by Exponentially Weighted Moving Averages. Management Science, 6, 324-342. https://doi.org/10.1287/mnsc.6.3.324

Zhang, H. (2013). Modeling and Forecasting Regional GDP in Sweden Using Autoregressive Models. Högskolan Dalarna University.

Zivot, E., \& Andrews, D. W. K. (1992). Further Evidence of Great Crash, the Oil Price Shock and Unit Root Hypothesis. Journal of Business and Economic Statistics, 10, 251-270. https://doi.org/10.1080/07350015.1992.10509904 